\title{
Clinical profiles of patients undergoing pacemaker implantation in India
}

Authors

\author{
Dr Mayank Jain ${ }^{1}$, Dr Priyanka Kiyawat ${ }^{2 *}$, Dr Surbhi Kiyawat ${ }^{3}$ \\ ${ }^{1}$ Consultant Interventional Cardiologist, Choithram Hospital \& Research Centre, Indore \\ ${ }^{2}$ Asst. Prof., Dept. of Pathology, MGM Medical College \& M.Y. Hospital, Indore \\ ${ }^{3}$ M.B.B.S/Physician, Private Practice \\ *Corresponding Author \\ Dr Priyanka Kiyawat
}

Asst. Prof., Dept. of Pathology, MGM Medical College \& M.Y. Hospital, Indore

\begin{abstract}
Background and Objective: The implantation of a permanent cardiac pacemaker for bradyarrhythmia management is one of the most commonly performed cardiac intervention. To study clinical profiles of patients undergoing permanent pacemaker implantation in India.

Material and Methods: This was an observational Study. Patients, who received permanent pacemaker for bradyarrhythmias from 1st September 2012 to 30th May 2018, were included in the study.A detailed analysis of demographic profile, and indications was performed.

Results: Out of 312 patients, vast majority of patients were elderly; with the majority being in the 56-88 years age group (75\%). Males received more pacemakers than females. Syncope was commonest presenting symptom and complete heart block was commonest ECG finding. Acquired A-V block was most common indication of pacing and Single chamber pacemaker (VVI/VVIR) was commonest mode of pacemaker.

Conclusion: Our study found that the major indications of pacemaker implantation were found to be acquired A-V block and SSS. Advanced age and male gender were associated with higher implantation rate.
\end{abstract}

Keywords: Clinical Profile, Pacemaker \& Bradyarrhythmias.

\section{Introduction}

Permanent pacemaker implantation is one of the most common therapeutic or prophylactic strategies in the management of patients with cardiac problems at present. ${ }^{1}$ Optimal selection of the single or dual chamber pacemaker devices depend in terms of arrhythmia, their cost effectiveness and longevity. ${ }^{2}$ However, considerable differences have been reported in the frequency of implantation of pacemakers and in the system selected. ${ }^{3,4}$
Studies discussing the clinical profile of the patients undergoing pacemaker implantation are available in Western literature, there are not many studies from the India, in view of which we conducted a study to assess clinical profile of the patients undergoing pacemaker implantation.

\section{Aims and Objectives}

To study clinical profiles of patients undergoing permanent pacemaker implantation in India. 
Study Design: Observational Study.

\section{Material and Methods}

This was an observational Study. Patients, who received a permanent pacemaker based on the ACC/AHA/HRS Guidelines for Device-Based Therapy of Cardiac Rhythm Abnormalities for bradyarrhythmias from 1st September 2012 to 30th May 2018, were included in the study, and were assessed for age, sex, symptoms, ECG finding, echocardiography, diagnosis, indication for pacemaker implantation, mode of pacemaker, and comorbidities. Patients with reversible bradyarrhythmias, drug induced bradycardia, electrolyte imbalance-induced bradyarrhythmias; patients not willing to participate in the study; and patients undergoing revision implantation; were excluded.

Continuous data are expressed as the mean value \pm 2 standard deviations. Percentage analysis was used to describe distribution of demographic variables.

\section{Results}

Table 1 shows the characteristics of study participants.

Table 1 Baseline Characteristics $(\mathrm{N}=312)$

\begin{tabular}{|l|c|}
\hline Characteristic & Mean, (Range) \\
\hline Age (Years) & No. $(\mathbf{\%})$ \\
\hline Sex & $200(64 . .10)$ \\
\hline Male & $112(35.89)$ \\
\hline Female & $213(68.26)$ \\
\hline Type of Pacemaker & $92(29.48)$ \\
\hline Single chamber pacemaker (VVI/VVIR) & 7 \\
\hline Double chamber pacemaker(DDD/DDDR) & \\
\hline VDD/VDDR & $\mathbf{2 5 6}(\mathbf{8 2 . 0 5})$ \\
\hline Indication for Pacemaker Implantation & $213(68.26)$ \\
\hline 1.Acquired A-V block & $43(13.78)$ \\
\hline (1.A) Complete heart block(CHB) & $\mathbf{5 0}(\mathbf{1 6 . 0 2})$ \\
\hline (1.B) Symptomatic high grade A-V block & $\mathbf{6 ( 1 . 9 2 )}$ \\
\hline 2.Sick sinus syndrome(SSS) & $213(68.26)$ \\
\hline 3. Permanent pacing in children & $168(53.84)$ \\
\hline Clinical Symptoms & $112(35.89)$ \\
\hline H/O Syncope & $54(17.30)$ \\
\hline fatigue & $53(16.98)$ \\
\hline Lightheadedness & $24(7.69)$ \\
\hline Palpitation & $244(78.20)$ \\
\hline Dyspnea & $72(23.07)$ \\
\hline Angina & $69(22.11)$ \\
\hline Comorbidities & $57(18.26)$ \\
\hline Hypertension & $46(14.06)$ \\
\hline Diabetes & $3(0.96)$ \\
\hline COPD & \\
\hline CAD & \\
\hline LV dysfunction $($ LVEF $\leq 50 \%)$ & \\
\hline CKD & \\
\hline Congenital Heart Disease & \\
\hline & \\
\hline
\end{tabular}

\begin{tabular}{|l|c|}
\hline Characteristic & Mean, (Range) \\
\hline Addiction & $60(19.23)$ \\
\hline Tobacco (Current) & $80(25.64)$ \\
\hline Tobacco (Former) & $18(5.76)$ \\
\hline Alcohol (Current) & $23(7.37)$ \\
\hline Alcohol (Former) & \\
\hline
\end{tabular}

\section{Discussion}

Our study was conducted to evaluate the clinical characteristics of patients underwent pacemaker implantation across India. In our study, out of 312 patients, $256(82.05 \%)$ patients were suffering from acquired AV block, in which 213 (68.26\%) had complete heart block (CHB) and $43(13.78 \%)$ had symptomatic high grade AV block.50 $(16.02 \%)$ patients were having sick sinus syndrome (SSS), In our study, acquired AV block was the most common indication for pacemaker implantation, perhaps because of the poor prognosis associated with it, whereas SSS does not decrease life expectancy. Mayosi et al in a retrospective study showed that ECG indications for pacing were atrio - ventricular block (62\%), sick sinus syndrome (25\%) and miscellaneous group $(13 \%) .{ }^{5}$ Brady et al in a retrospective study survival data from 546 elderly patients found the indications for pacing were A-V block (52\%) and sick sinus syndrome $(48 \%){ }^{6}$ Uslan et al showed that overall $55.2 \%$ of permanent pacemaker implantation recipients had an indication of atrioventricular block, $22.8 \%$ sinus node dysfunction, $10 \%$ bilevel conduction defect (both atrioventricular block and sinus node dysfunction). ${ }^{7}$

Youngest patient in our study was 04 years old, and the mean age of study group was $64.71 \pm$ 14.75 years. Majority of patients $(75 \%)$ of patients were in 56-88 years of age group. These results are consistent with previous studies. ${ }^{8,10,11} .92 \%$ patients were symptomatic at presentation, and syncope $(68.26 \%)$ was the most common symptom; were comparable with previous studies. $^{8-16}$

Hypertension (78.20\%) was the most common associated co-morbidity and $23.07 \%$ patients were diabetic, consistent with previous studies. ${ }^{17}$

$68.26 \%$ patient underwent single chamber (VVI/VVIR) pacemaker implantation. Dual chamber (DDD/DDDR) pacemaker was implanted 
in $29.48 \%$ of patients. Financial constraint was the major factor for single chamber pacemaker implantation. Chauhan et al. ${ }^{18}$ performed a study on a total of 2019 patients who underwent new pacemaker implantation, and of the total, 1733 patients $(85.8 \%)$ received a VVI pacemaker and $286(14.2 \%)$ a DDD pacemaker.

\section{Conclusion}

Total of 312 patients underwent pacemaker implantation; Acquired A-V block was the most common indication. Single chamber (VVI/VVIR) was the most common mode of implanted pacemaker. Most of the patients were symptomatic due to bradyarrhthymias and syncope was the most common indication. Advanced age and male gender were associated with higher implantation rate.

\section{References}

1. Lopez-Jimenez F, Goldman L, Orav EJ, Ellenbogen K, StamblerB, Marinchak R, Wilkoff BL, Mangione CM, Yoon C, Vitale K, LamasGA. Health values before and after pacemaker implantation. American Heart Journal. 2002;144(4):687-92.

2. Brunner M, Olschewski M, Geibel A, Bode C, Zehender M.Long-term survival after pacemaker implantation: Prognostic importance of gender and baseline patient Characteristics. European Heart Journal. 2004; 25, 88-95.

3. European Working Group on Cardiac Pacing. Cardiac pacing. European Heart Journal. 1987;8 (suppl F):212.

4. Ray SG, Griffith MJ, Jamieson S, Bexton RS, Gold RG. Impact of the recommendations of the British Pacing and Electrophysiology Group on pacemaker prescription and on the immediate costs of pacing in the Northern region. British Heart Journal.1992;68:5314.

5. Mayosi BM, Little F, Millar RN. Longterm survival after permanent pacemaker implantation in young adults: 30 year experience. Pacing Clin Electrophysiol 1999; 22: 407-12.

6. Brady PA, Shen WK, Neubauer SA, et al. Pacing mode and long-term survival in elderly patients with congestive heart failure: 1980-1985. J Interv Card Electrophysiol 1997; 1:193-201.

7. Uslan DZ, Tleyjeh IM, Baddour LM, et al. Temporal trends in permanent pacemaker implantation: a population-based study. Am Heart J 2008; 155:896-903.

8. Lone NA, Khan KA, Jalal S, Jan VM, Rather HA, Nazir S, et al. Clinicalprofile and outcome in patients with bifascicular block: The role of invasive electrophysiological study in planning treatment. Journal of Chinese Clinical Medicine 2010;5:19-25.

9. Shaw DB, Holman RR, Gowers JI. Survival in sinoatrial disorder (sick sinus syndrome). Br Med J 1980;280:139-41.

10. Levine SA, Miller H, Penton GB. Some clinical features of complete heart block. Circulation 1956;13:801-24.

11. Rubenstein JJ, Schulman CL, Yurchak PM, DeSanctis RW. Clinical spectrum of the sick sinus syndrome. Circulation 1972;46:5-13.

12. Jensen G, Sigurd B, Meibom J, Sandoe E. Adams-Stokes syndrome caused by paroxysmal third-degree atrioventricular block. Br Heart J I973;35:516-20.

13. Sigurd B, Jensen G, Meibom J, Sandoe E. Adams-Stokes syndrome caused by sinoatrial block. Br Heart J 1973;35:10028.

14. Sigurd B, Sandøe E. Management of Stokes-Adams syndrome. Cardiology 1990;77:195-208.

15. Hart WJ. The neurological presentation of sick sinus syndrome. Can Fam Physician 1979;25:1233-41.

16. Epstein AE, DiMarco JP, Ellenbogen KA, Estes NA 3rd, Freedman RA, Gettes LS, et al. American College of Cardiology 
Foundation; American Heart Association Task Force on Practice Guidelines; Heart Rhythm Society. 2012 ACCF/AHA/HRS focused update incorporated into the ACCF/AHA/HRS 2008 guidelines for device-based therapy of cardiac rhythm abnormalities: A report of the American College of Cardiology Foundation/ American Heart Association Task Force on Practice Guidelines and the Heart Rhythm Society. Circulation 2013;127: e283-352.

17. Movahed MR, Hashemzadeh M, Jamal MM. Increased prevalence of third-degree atrioventricular block in patients with type II diabetes mellitus. Chest 2005;128:26114.

18. Chauhan A, Grace AA, Newell SA, Stone DL, Shapiro LM, Schofield PM, et al. Early complications after dual chamber versus single chamber pacemaker implantation. Pacing Clin Electrophysiol 1994;17:2012-5. 